\title{
Epidemiology and Comparison of Methods for Diagnosis of Entamoeba Histolytica in Stool and Serum Specimens among School Children in Lagos State, Southwest, Nigeria
}

\author{
Muoneke Peter Declan' PhD, "Okanlawom Babatunde Meshach ${ }^{2}$ M.Sc, Adekunle Oluwatoyin \\ Christianah $^{1}$ PhD, Rachel Adekemi Akanni1 M.Sc, Sanusi Tawakalit Omotayo ${ }^{3}$ M.Sc, Adefioye \\ Olusegun Adelowo ${ }^{1}$ M.Sc, Ojurongbe Olusola ${ }^{1}$ PhD
}

\author{
${ }^{1}$ Department of Medical Microbiology and Parasitology, College of Health Sciences, Ladoke Akintola University of \\ Technology, P.M.B. 4400, Osogbo Nigeria. \\ ${ }^{2}$ Department of Medical Laboratory Science, College of Health Sciences, Ladoke Akintola University of Technology, \\ P.M.B. 4400, Osogbo, Nigeria. \\ ${ }^{3}$ Department of Community Medicine, College of Health Sciences, Ladoke Akintola University of Technology, P.M.B. \\ 4400, Osogbo, Nigeria. \\ *Corresponding Author \\ Mr. Okanlawon Babatunde Meshach \\ Department of Medical Laboratory Science \\ Ladoke Akintola University of Technology \\ Osogbo, Osun State \\ Nigeria \\ Email: bmokanlawon@lautech.edu.ng
}

Received:18 December 2019; $\mid$ Revised:21 January 2020; $\mid$ Accepted:10,June,2020

\begin{abstract}
Entamoeba histolytica, the causative agent of amoebiasis infection is second to malaria as a major protozoan cause of morbidity and mortality worldwide, especially in developing countries. This study was designed to determine the prevalence of Entamoeba histolytica infection using microscopy and Enzyme Linked Immunosorbent Assay (ELISA) techniques and its contribution to the development of anaemia among primary school children. Five hundred and forty faecal and blood samples were collected and examined according to World Health Organisation standard using direct saline-iodine and floatation techniques and ELISA kit was used to determine E. histolytica antibody quantitatively. Overall prevalence by microscopy and ELISA were $10.9 \%, 49.6 \%$ respectively. Male $(13.3 \%)$ were more infected than female $(8.6 \%)(\mathrm{P}>0.05)$ and age group 2-5years had the highest prevalence rate of $12.2 \%$, while age group 69years $(10.2 \%)$ had the least $(\mathrm{P}>0.05)$. The mean serum ferritin of uninfected and infected school children are $73.61 \pm 11.58,76.00 \pm 11.51$ respectively $(\mathrm{P}<0.05)$, while the mean packed cell volume of uninfected and infected school children are $38.19 \pm 2.74,38.06 \pm 3.92$ respectively $(\mathrm{P}>0.05)$. Personal and environmental hygiene, public awareness and regular mass treatment programme should be sustained as this would reduce the burden of intestinal protozoal infection among school children.
\end{abstract}




\section{Introduction}

Entamoeba histolytica is the causative agent of amoebiasis which is pseudopod-forming nonflagellated protozoan parasite ${ }^{[15]}$. The $E$. histolytica life cycle consists of an infective cyst and an invasive trophozoite form. Infection is acquired by ingestion of food or water containing the cyst form of Entamoeba histolytica parasite, which is responsible for amoebic colitis and liver abscess [16]. In developing world, Entamoeba histolytica infections are second to malaria as a protozoan cause of death worldwide ${ }^{[19]}$. About 50 million people are believed to be infected at any one time, and up to 100,000 deaths occur per year ${ }^{[12]}$. Although cosmopolitan in distribution, it mainly occurs in the tropics and sub tropics and other places especially in areas where there is low level of sanitation and very poor personal hygiene practices [13]. The prevalence of Entamoeba histolytica infection is as high as $50 \%$ in areas of Central and South America, Africa and Asia ${ }^{[16]}$. In Nigeria, amoebiasis is prevalent and widespread which has been attributed to quite a number of multiple environmental sources of transmission such as poor education, poverty, overcrowding, contaminated water supply, and unsanitary conditions ${ }^{[9,14]}$. The several surveys have indicated a high prevalence of Entamoeba histolytica infections among Nigerian children in different localities ${ }^{[10]}$. In Anambra State, Southeastern part of Nigeria, the prevalence of $E$. histolytica infection was found to be $12.6 \%{ }^{[10]}$.

Infection with $E$. histolytica may be asymptomatic or cause intestinal or extraintestinal disease ${ }^{[10]}$. Asymptomatic infection with $E$. histolytica is associated with a positive serum amoebic anti-amoebic antibody and a positive stool antigen test. Clinical syndromes associated with intestinal E. histolytica disease are bloody diarrhoea, weight loss, fatigue, abdominal pain, acute rectocolitis, fulminant colitis (acute necrotizing colitis) with perforation, toxic megacolon, chronic non dysenteric colitis, amoeboma, and perianal ulceration ${ }^{[10]}$. Liver abscesses due to amoebiasis are ten times more frequent in adults than in children. Very young seem to be pre-disposed to fulminant colitis. Amoebic colitis affects both sexes equally [15].

Various virulence factors of E. histolytica such as adhesins, toxins, amoebapores and proteases are powerful weapons that lead to the lysis, death and eventually destruction of the host tissues ${ }^{[5]}$. Entamoeba dispar which is non-pathogenic, noninvasive protozoa and cannot be distinguished morphologically from E. histolytica is ten times more common than Entamoeba histolytica and can only be detected by molecular-based techniques ${ }^{[6]}$. However, only $10 \%$ of E. histolytica infections cause invasive disease. Hence, only $1 \%$ of persons with stool microscopy findings that reveal Entamoeba develop symptomatic amoebiasis. E. histolytica can be diagnosed routinely using faecal samples because results are available quickly but certain other species are impossible to distinguish by microscopy alone ${ }^{[1]}$. There are presently several commercially available antigen kits for detecting Entamoeba antigen in stools, these tests however require fresh stool for analysis, and only a few kits have been reported to be specific for E.histolytica not $E$. dispar.

The aim of the study was therefore, designed to determine the prevalence of $E$. histolytica among school children in Lagos State, Nigeria using two different methods of diagnosis and also to determine the association of $E$. histolytica infection in relation to packed cell volume (PCV) and serum ferritin.

\section{Materials and Methods}

\subsection{Study Location}

The study was carried out in five local Government Areas within Lagos State which comprise: Mushin, Surulere, Ajeromi-Ifelodun, Badagry and Ojo Local Government Areas with estimated populations of 633,$009 ; 503,975$; 684,$105 ; 426,735$ and 598,071 respectively according to the 2006 population census. These areas are located in the rain forest area with distinct rainy and dry seasons. These local government areas are predominantly with clustered homes, poor sanitary conditions and are densely populated with indiscriminate disposal of human wastes in 
drainages, streams and rivers. School children within the age bracket 2-13 years were recruited for the study. The children were randomly selected from the schools in all the five local government areas.

\subsection{Study design}

A total number of five hundred and forty (540) school children were examined for Entamoeba histolytica infection. The parasitological survey was preceded by a pre-survey contact during which verbal permission was obtained from the Ethical review Committee and parents of the participating school children.

\subsection{Sample Collection}

School children were educated on how to collect fresh morning stool sample into sterile containers which were labeled and distributed to each of the participating school children a day preceding the program. Stool samples were collected as soon as they arrived at the school premises, and were packaged and transported to the laboratory for examination ${ }^{[8]}$. Three millilitres of venous blood sample was collected from each of the participants and transferred into EDTA containers and mixed gently ${ }^{[7]}$.

\subsection{Sample Analysis and Identification}

Stool samples were visually examined to note the consistency, presence of abnormal features; whether watery, bloody, with mucus, formed or unformed ${ }^{88}$. Direct smear saline-iodine preparation and floatation techniques of stool samples were examined for cyst or trophozoite of Entamoeba histolytica parasites under the microscope using x 10 and $\mathrm{x} 40$ objectives lenses as recommended by World Health Organisation ${ }^{[8]}$.

\subsection{Determination of Packed Cell Volume and Serum Ferritin}

The packed cell volume (PCV \%) was determined by centrifuging microhematocrit tubes filled with whole blood in a microhaematocrit rotor for $5 \mathrm{~min}$ at $10,000 \mathrm{rpm}$ and was read with the haematocrit reader ${ }^{[7]}$ while serum ferritin was estimated using commercially available rapid test kit produced by TECO DIAGNOSTICS, Lakeview
Ave. Anaheim CA U. S.A. The procedure was according to the manufacturer's instruction.

\subsection{Enzyme Immunoassay for the detection of $E$. histolytica}

Enzyme immunoassay was used for the quantitative determination of E. histolytica antibody in serum using commercially available test kits by Diagnostic Automation/ Cortez Diagnostics, Inc. Calabsas, CA USA. The assay was carried out according to the manufacturer's instruction.

\subsection{Statistical analysis}

Data analysis was carried out using SPSS version 16. Frequency tables and cross tabulations were produced for each of the study variables. Relationship between independent and dependent variables was assessed using chi-square test. Statistical significance was achieved if $\mathrm{P}<0.05$.

\section{Results}

A total number of five hundred and forty (540) stool and blood samples were examined from school children in the study areas. The mean age and mean packed cell volume were $7.5 \pm 2.78$ and $37.81 \pm 2.4$ respectively while the mean serum ferritin $\pm \mathrm{SD}$ was 74. $6 \pm$ 9.62. Age group 6-9 years had the highest number of participants $(43.5 \%)$ while age group 10-13 years had the least (24.6\%). The male to female ratio was 27.1: 26.9 (Table 1).

Prevalence of Entamoeba histolytica infection among school children by age and sex is shown in Table 2. The prevalence of Entamoeba histolytica was $10.9 \%$. Age group 2-5years had the highest prevalence rate of $12.2 \%$ while age group 6-9years had the least $(10.2 \%)$. There was no significant difference between age group and Entamoeba histolytica infection $(\mathrm{p}=0.3707)$. Male $(13.3 \%)$ were more infected than their female counterpart $(8.6 \%)$ and there was no significant difference between Entamoeba histolytica infection and age (p $=0.723$ ).

The association of Entamoeba histolytica infection in relation to packed cell volume and serum ferritin is shown in Table 3. Non infected school children had more mean packed cell volume $(38.19 \pm 2.74)$ than the infected ones $(38.06 \pm 3.92)$ and there is no significant difference between 
packed cell volume and Entamoeba histolytica infection $(\mathrm{P}=0.5897)$. The case was not the same with serum ferritin in which infected school children had more mean serum ferritin (76.00 \pm 11.51) than the uninfected ones $(73.61 \pm 11.58)$, thus there was significant association between serum ferritin and Entamoeba histolytica infection $(\mathrm{P}=0.0026)$
Table 4 shows the detection of E.histolytica infection among school children using ELISA and microscopy methods. With microscopy, the prevalence of E.histolytica was $10.9 \%$ while it was 49.6\% using ELISA. Detection rate for microscopy method was $22.1 \%$ while the ELISA method was $100 \%$.

Table 1: Characteristics of study subjects of Entamoeba histolytica based on different diagnostic methods

\begin{tabular}{|l|l|}
\hline Characteristics & Number $\mathbf{( \% )} \mathbf{n}=\mathbf{5 4 0}$ \\
\hline Age Group & $172(31.9)$ \\
$2-5$ & $235(43.5)$ \\
$6-9$ & $133(24.6)$ \\
$10-13$ & \\
Sex & $271(51.0)$ \\
Male & $269(49.0)$ \\
Female & $7.5 \pm 2.78$ \\
Mean age \pm SD & $37.81 \pm 2.4$ \\
Mean PCV \pm SD & $74.63 \pm 9.62$ \\
Mean Serum ferritin \pm SD & $59(10.9)$ \\
E. histolytica positive by Microscopy & $268(49.6)$ \\
E. histolytica positive by ELISA & \\
\hline
\end{tabular}

Table 2: Prevalence of Entamoeba histolytica infection among school children by age and sex

\begin{tabular}{|l|l|l|l|l|}
\hline Parameter & No. Examined & No. Infected & \% Infected & P-value \\
\hline Age Group & & & & \\
$2-5$ & 172 & 21 & 12.2 & \\
$6-9$ & 235 & 24 & 10.2 & 0.3707 \\
$10-13$ & 133 & 14 & 10.5 & \\
Total & 540 & 59 & 10.9 & \\
Sex & & 36 & 13.3 & \\
Male & 271 & 23 & 8.6 & 0.723 \\
Female & 269 & 59 & 10.9 & \\
Total & 540 & & & \\
\hline
\end{tabular}

Table 3: Association of Entamoeba histolytica infection in relation to Packed Cell Volume and serum ferritin

\begin{tabular}{|l|l|l|}
\hline Parameter & Volume & P- value \\
\hline Mean Pack Cell Volume & & \\
$\mathbf{( \% )}$ & $38.06 \pm 3.92$ & 0.5897 \\
Infected \pm SD & $38.19 \pm 2.74$ & \\
Non infected \pm SD & & \\
Mean Serum Ferritin & $76.00 \pm 11.58$ & 0.0026 \\
/Ug & $73.61 \pm 11.51$ & \\
Infected \pm SD & & \\
Non infected \pm SD & & \\
\hline
\end{tabular}


Table 4: Detection of Entamoeba histolytica infection among School children Using ELISA and Microscopy methods

\begin{tabular}{|l|l|l|l|}
\hline \multicolumn{1}{|c|}{ Methods } & \multicolumn{2}{|c|}{ Number } \\
\cline { 2 - 4 } & Positive & Negative & $\begin{array}{l}\text { Detection rate among positive } \\
\text { participants (n= 268) }\end{array}$ \\
\hline $\begin{array}{l}\text { Microscopy } \\
\text { ELISA }\end{array}$ & 59 & 481 & $59(22.1 \%)$ \\
\hline
\end{tabular}

\section{Discussion and Conclusion}

Entamoeba histolytica is second to malaria as a protozoan cause of death worldwide ${ }^{[19]}$. About 50 million people are believed to be infected at any one time, and up to 100,000 deaths occur per year ${ }^{[12]}$. Although cosmopolitan in distribution, it mainly occurs in the tropics and sub tropics and other places especially in areas where there is low level of sanitation and very poor personal hygiene practices [13]. In this study, the prevalence of Entamoeba histolytica by direct saline-iodine examination of stool samples microscopically was $10.9 \%$ while by ELISA using serum samples was $49.6 \%$. The difference in the prevalence of $E$. histolytica showed that direct stool microscopy method alone was not effective any longer for the diagnosis of amoebiasis and this is in tandem with the report of Haque et. al. ${ }^{[11]}$. The prevalence rate of $10.9 \%$ by direct saline-iodine method was similar to the work conducted in Anambra State, Southeastern part of Nigeria by Aribodor et.al., ${ }^{[10]}$ with prevalence rate of $12.6 \%$ and almost similar with Akingbade et. al., ${ }^{[18]}$ in Abeokuta, Southwestern part of Nigeria with prevalence rate of $19.4 \%$. The prevalence of $E$. histolytica recorded in this study is quite lower than those obtained in Kano by Ibrahim, ${ }^{[13]}(45.0 \%)$ and in Kaduna by Obadiah ${ }^{[17]}$ (37.6\%). In Nigeria, amoebiasis is prevalent and widespread which has been attributed to quite a number of multiple environmental sources of transmission ${ }^{[9,14]}$. Several surveys have indicated a high prevalence of Entamoeba histolytica infections among Nigerian children in different localities ${ }^{[10]}$.

In this study, the highest prevalence of Entamoeba histolytica infection was recorded in age group 2-5years (12.2\%), followed by age group 1013 years $(10.5 \%)$ and the least age group was 69years $(10.2 \%)$. This result is in agreement with the work of Simon-Oke and Ogunleye, ${ }^{[22]}$ which also recorded highest prevalence among the same age group but not in tandem with the work of Oti et. al., ${ }^{[23]}$ who recorded highest prevalence among the age group 6-10. Besides, there was no significant association between age and Entamoeba histolytica infection $(\mathrm{P}=0.3707)$. The reduction in prevalence as the age increases could be associated with a higher level of awareness of personal hygiene as they grow older. It was observed that male (13.3\%) school children have higher prevalence than their female counterparts $(8.6 \%)$ and the difference was not statistically significant $(\mathrm{P}=0.723)$. This agreed with the work of Aribodor et al. ${ }^{[10]}$ that showed that males $(16.1 \%)$ were more infected than females who had a prevalence rate of $9.3 \%$. Although, gender is not a significant risk factor for the prevalence of Entamoeba histolytica infection, it is however important to note that more males were enlisted in the study than females.

Mean serum ferritin levels was higher in infected school children $(76.00 \pm 11.58 \mathrm{ug} / \mathrm{ml})$ than their non-infected counterparts $(73.61 \pm 11.51 \mathrm{ug} / \mathrm{ml})$ and there was no significant difference between packed cell volume and Entamoeba histolytica infection $(\mathrm{P}=0.5897)$. This result agreed with Silva et al., ${ }^{[20]}$ but not with Le et. al., ${ }^{[21]}$ who showed that mean serum ferritin was concentrated more among non-infected school children than infected with Entamoeba histolytica. Statistical analysis showed that there was significant association between serum ferritin and E.histolytica infecti.on $(\mathrm{P}=0.0026)$. The packed cell volume (PCV) recorded in this study varied between infected school children when compared with non-infected school children. The results showed that mean packed cell volume was higher in non- infected school children $(38.19 \pm 2.74)$ than in infected ones $(38.06 \pm 3.92)$ and there was no significant association between packed cell volume and E.histolytica infection $(\mathrm{P}=0.5897)$. 
In this study, ELISA was able to detect $E$. histolytica when compared with microscopy. ELISA showed a better sensitivity than microscopy because microscopy cannot distinguish between $E$. histolytica and other forms of amoebiasis such as $E$. dispar. Generally in terms of sensitivity and specificity, most studies have shown microscopy to be more sensitivity and specific than ELISA. A study conducted in Turkey reported microscopy as being more sensitive and specific than ELISA in the detection of E. histolytica ${ }^{[4]}$. Another sets of studies in Kilimanjaro and New Delhi also reported microscopy as being more sensitive than ELISA in the detection of $E$. histolytica ${ }^{[2,3]}$. The higher detection rate in this study is attributed to the fact that ELISA IgG was used which is an indication of high exposure rate rather than high positivity rate in the study area. The high IgG rate means that most of the participants have been exposed to the parasite which is an indication that the parasite may be endemic in this environment. This study is limited in several aspects as we did not cover most senatorial area and this is due to financial constraint. A future study needs to be done in order to include other senatorial districts in the study area, so that a larger, more representative sample size for the state would be collected for analysis.

Amoebiasis can be prevented by increased sanitation, effective and safe disposal of human waste. Travelers should avoid unwholesome fruits and fresh vegetables of doubtful sources. They should drink only boiled or bottled water. Avoiding sexual practices that involve faecal-oral contact can reduce infection in homosexuals. In mental institutions recurrent outbreaks of amoebiasis can be prevented by routine screening of stool and adequately treating infected patients.

\section{References}

1 Lau YL, Anthony C, Fakhrurrazi SA, Ibrahim J, Ithoi I, Mahmud R. Real-time PCR assay in differentiating Entamoeba histolytica, Entamoeba dispar, and Entamoeba moshkovskii infections in Orang Asli settlements in Malaysia. Parasit Vectors 2013; 6(1): 250 DOI: $10.1186 / 1756-3305-6-250$

2 Nesbitt RA, Mosha FW, Katki HA, Ashraf M, Assenga C, Lee CM. Amebiasis and comparison of microscopy to ELISA technique in detection of Entamoeba histolytica and Entamoeba dispar. J Natl Med Assoc 2004; 96(5): 671-677

3 Srujana, M., Nisha, S. and Monorama, D. Microscopy versus ELISA test for the detection of Entamoeba histolytica infection in stool samples. Trop. Parasitol. 2014; 4(4): 136-138.

4 Tuzemen NU, Dogan N. Comparison of direct microscopy, culture, ELISA and molecular methods for diagnosis of Entamoeba histolytica. Mikrobiyol Bul 2014; 48(1): 114 122 [PMID: 24506721]

5 Serrano-Luna J, Pina-Vazquez C, Reyes-Lopez M, Ortiz-Estrada G, de la Garza M. Proteases from Entamoeba spp. and Pathogenic FreeLiving Amoebae as Virulence Factors. J Trop Med 2013; 2013: 890603 DOI: $10.1155 / 2013 / 890603$

$6 \mathrm{WHO} / \mathrm{PAHO} / \mathrm{UNESCO}$ Report. A consultation with experts on amoebiasis. Mexico City, Mexico, 28-29 January, 1997. Epidemiol Bull, 1997; 18: 13-4.

7 Cheesbrough, M.District Laboratory Practice in Tropical Countries: Part 1 (2nd ed). Cambridge University Press, London, 2005; pp 197-199

8 Partners for Parasite Control: Geographical distribution and useful facts and stats.World Health Organization (WHO) 2007; pp 14

9 Ajero,C.M., Nwoko, B.E.B., Nwoke, E.A., and Ukaga, C.N. Human Amoebiasis: Distribution and burden and the Nigerian Environment. International Science Research Journal, 2008; 1(2):130-134.

10 Aribodor, D.N., Anidebe, A.O., Eneanya, O.A. and Emelummadu, O.F. Entamoeba histolytica infection in children aged 0-12 years in rural communities in Anambra State. Nigerian Journal of Parasitology, 2012; 33(2): 129-132.

11 Haque R, Mollah NU, Ali IK, Alam K, Eubanks A, Lyerly D, Petri WA, Jr. Diagnosis of amebic liver abscess and intestinal infection with the TechLab Entamoeba histolytica II antigen detection and antibody tests. J Clin Microbiol 2000; 38(9): 3235-3239 
12 Haque R, Petri WA, Jr. Diagnosis of amebiasis in Bangladesh. Arch Med Res 2006; 37(2): 273-276 DOI: $10.1016 /$ j.arcmed.2005.09.001

13 Ibrahim,S.Transmission of Amoebiasis at some selected areas of Kano State, Nigeria: The role of Human faeces used as manure. Bayero Journal of Pure and Applied Sciences, 2008; 1(1): 32-35.

14 Inabo, H.G., Galadima, M., Ogbodu, L.J. and Okuofu, C.A. Prevalence of E.histolytica and G. lamblia primary school pupil in five rural villages around Kaduna and Zaria. Nigeria Journal of Parasitology, 2014; 21: 61-68.

15 Stanley Jr,S.L.Amaoebiasis. Lancet, 2003; 361(9362): 1025-34.

16 Tengku SA, Norhayati M. Public health and clinical importance of amoebiasis in Malaysia: a review. Trop Biomed 2011; 28(2): 194-222

17 Obadiah, H. I.Review of the survey of Entamoeba histolytica in Children a Brief Focus on Nigeria Situation. Journal of Physiology and Pharmacology Advances, 2012; 2(3): 150-157.

18 Akingbade, O. A.,Akinjimi, A. A., Ezechukwu, U. S., Okerentugba, P. O. and Okonko, I. O. Prevalence of Intestinal Parasites among Children with Diarrhea in Abeokuta, Ogun State, Nigeria. Researcher, 2013; 5(9): 66-73
19 Schmidt, G. D. and Roberts, L. S. Foundations of Parasitology, 6th edition. New York. Mc Graw-Hill Higher Education, 2009; pp 767

20 Silva RR, da Silva CA, de Jesus Pereira CA, de Carvalho Nicolato RL, Negrao-Correa D, Lamounier JA, Carneiro M. Association between nutritional status, environmental and socio-economic factors and Giardia lamblia infections among children aged 6-71 months in Brazil. Trans R Soc Trop Med Hyg 2009; 103(5): 512-519 [PMID: 19054535 DOI: 10.1016/j.trstmh.2008.10.019]

21 Le HT, Brouwer ID, Verhoef H, Nguyen KC, Kok FJ. Anemia and intestinal parasite infection in school children in rural Vietnam. Asia Pac J Clin Nutr 2007; 16(4): 716-723

22 Simon-Oke, I.A and Ogunleye, E.Prevalence of Entamoeba histolytica among primary school children in Akure, Ondo State, Nigeria. Journal of Public Health and Epidemiology, 2015; 7(11): 346-351.

23 Oti, B. V., Galleh, P. R., Ezhim, I. M., Tsaku, A. P., Ajegena, S. A., Oti, C. A. and Oti, B. I. Prevalence of Entamoeba histolytica Infection Using Microscopy and Adhesin Detection Methods among School Children in Central Nigeria. Asian Journal of Biology, 2017, 2(4): 2456-7124 